\title{
La ética médica a comienzos del siglo XX: "La montaña mágica" de Thomas Mann
}

\author{
Gustavo Figueroa ${ }^{1}$
}

Resumen: La bioética ha transformado la ética médica de manera profunda, apelando a otros principios y prácticas. El presente trabajo intenta comprender la ética médica occidental tradicional recurriendo a su descripción en la narrativa artística, porque esta describe con especial calidad y rigor el modo como se la entendía y ejercía antes del giro bioético. Se escogió la obra de Thomas Mann "La montaña mágica” porque, además de su valor intrínseco, su punto de vista esclarece otros fundamentos morales que pueden haberse mal entendido, descalificado o perdido en los últimos ańos. Así la ética del bien predominaba sobre la ética del deber, la vida buena sobre la obligatoriedad, la estima de sí por encima del respeto del otro, los máximos alcanzables por encima de los mínimos exigibles.

Las ácidas críticas expresadas por el narrador omnisciente insinúan que esta manera de entender el comportamiento moral en medicina necesitaba complementarse con otras visiones éticas.

Palabras clave: bioética, obra de arte, bien, deber, cuidado

\section{Medical ethics in the beginning of twentieth century. "The magic mountain" of Thomas Mann}

Abstract: Bioethics has deeply transformed medical ethics, appealing to other principles and practices. The present work tries to understand traditional western medical ethics by recurring to its description in artistic narrative, because this describes with special quality and rigor the way it was understood and practiced before the bioethics turn. The work of Thomas Mann "The magic mountain" was chosen because, besides its intrinsic value, its point of view clears other moral foundations which could have been mal interpreted, disqualified or lost in the last years. Thus, the ethics of goodness predominated over the ethics of duty, the good life over obligation, self esteem over respect for the other, maximum achieved over minimum required.

The acid critiques expressed by the omniscient narrator insinuate that this way of understanding moral behavior in medicine needs to complement other ethical views.

Key words: bioethics, art work, goodness, duty, care

\section{A ética médica no começo do século XX: “A montanha mágica” de Thomas Mann}

Resumo: A bioética transformou a ética médica de maneira profunda, apelando para outros principios e práticas. O presente trabalho tenta compreender a ética médica ocidental tradicional recorrendo à sua descrição na narrativa artística, porque esta descreve com especial qualidade e rigor o modo como era entendida e exercida antes da construçáa bioética. Foi escolhida a obra de Thomas Mann "A montanha mágica” porque, ademais de seu valor intrínseco, o seu ponto de vista esclarece outros fundamentos morais que podem ter sido mal entendidos, desqualificados ou perdidos nos últimos anos. Assim a ética do bem predominava sobre a ética do dever, a vida boa sobre a obrigatoriedade, a estima de si acima do respeito ao outro, os máximos alcançáveis acima dos mínimos exigidos. As ácidas críticas expressadas pelo narrador onisciente insinuam que esta maneira de entender o comportamento moral na medicina necessitava complementar-se com outras visóes éticas.

Palavras-chave: bioética, obra de arte, bem, dever, cuidado

\footnotetext{
${ }^{1}$ Médico psiquiatra, Profesor Titular del Departamento de Psiquiatría, Escuela de Medicina, Universidad de Valparaíso, Chile Correspondencia: gfigueroacave@gmail.com
} 
La ética médica, resultado de una tradición ininterrumpida que se remonta a la Grecia clásica, posterior al giro provocado por el nacimiento de la bioética ha sido mal interpretada en algunos postulados fundamentales y desconocida en el alcance de ciertas prácticas originales. De manera inadvertida, la bioética ha reflexionado y entendido la historia de la ética en medicina a partir del presente, de modo que conceptos actuales han servido para comprender situaciones radicalmente distintas; por ejemplo, aplicando la noción de "beneficencia", o su discutible traducción de "paternalismo", se ha creído caracterizar épocas o actuaciones profesionales pretéritas sin ahondar suficientemente en las experiencias originarias $(1,2)$. Lo mismo ocurrió con la conocida frase de Toulmin de que "la medicina (bioética) ha salvado a la ética", la que condujo, sin pretenderlo, a no reparar en importantes logros o a suponerse un anquilosamiento de los modos de conducirse de los médicos y personal de salud desde los tiempos de la Edad Media y el Renacimiento(3,4).

Por otra parte, surge la pregunta inversa, esto es, si la bioética olvidó o dejó en segundo plano conquistas que, siendo decisivas, no parecen importantes hoy porque surgen de premisas distintas. La amistad del médico, por tomar una expresión de Aristóteles, puede que haya sido descuidada porque no coincide con los postulados modernos de una práctica centrada en la dimensión técnica, logros medibles y criterios objetivos; peor aún, casi ni se la menciona como digna de ser investigada o problematizada (5-11).

$\mathrm{El}$ arte es una forma privilegiada de abrir y esclarecer la realidad de un modo absolutamente original y tan diferente al científico que, más que opuesto, se puede postular que complementario para "saber arreglárselas con la existencia". Y esto es especialmente valedero en el campo de la medicina y su vertiente moral, donde la creación y obra artísticas han jugado un papel tan fundamental porque son una modalidad de tékne, formas peculiares de producir(12-18). Por algo Heidegger advirtió de manera expresa que el que "se pueda investigar al ser humano (...) desde la perspectiva de las ciencias naturales no prueba en modo alguno que en eso "orgánico», en el cuerpo científicamente explicado, resida la esencia del hombre", aun "podría ser que la naturaleza ocul- tase su esencia en la cara que presenta al dominio técnico (científico)" (19).

En 1924 apareció la monumental obra de Thomas Mann "La montaña mágica" (20). Más allá de sus méritos indudables, que hicieron merecedor a su autor del Premio Nobel de Literatura, la novela nos narra la historia del joven Hans Castorp y sus siete años pasados en el Sanatorium Berghof de Davos-Dorf — "la montaña mágica”- a causa de una tuberculosis pulmonar. Indudablemente que, como producto artístico original, la profundidad y alcances de su contenido no se pueden reducir a unos pocos temas que se dejen resumir en un par de líneas. Pero Ricouer tiene razón cuando asevera que se trata de una Bildungsroman, novela educativa o de aprendizaje espiritual, que sigue la tradición romántica alemana desde Goethe y su famoso Wilhelm Meisters Lehrjahre(21). Pero va más allá, porque la búsqueda interior del héroe se lleva a cabo al hilo de una triple fábula o eje: del tiempo — su supresión, descomposición o destemporalización-, derrumbe irremisible de la sofisticada cultura occidental europea, premonitoria de la Gran Guerra y la experiencia íntima de la enfermedad mortal $(22,23)$. Esta última es la que nos interesa en estos momentos, porque nos proporciona un acceso privilegiado al mundo de la medicina de comienzos del siglo XX, medicina científica de la más alta calidad porque provenía del mundo alemán.

El narrador, puesto en primer plano con ostentación, insistencia y obstinación, nos enfatiza en su Vorsatz, prólogo, que su historia "proviene antes de cierto cambio y de cierto límite que han trastornado profundamente la Vida y la Conciencia (...) El carácter antiguo de una historia, ¿no es tanto más profundo, más completo y más legendario, cuando se desarrolla en un pasado cercano al presente?”. Así, si su perspectiva no es la de hoy, empero nos atañe por su proximidad, y si su intención no es la anécdota sino ahondar en los enigmas del ser humano, de ahí surgen los objetivos de nuestro trabajo. Por una parte, estudiar la ética médica tal como se llevaba a cabo y conducía a comienzos del siglo XX y, por otra, sacar algunas consecuencias que puedan ayudar a poner en perspectiva nuestra bioética presente, cuando ya lleva más de un cuarto de siglo de existencia. 
Sin embargo, debemos ser cautos, como nos lo recuerda constante e irónicamente este narrador omnipresente que nos va instruyendo y orientando durante todo el relato. Se trata de una ficción y no de la realidad, de narración y no demostración, del enfermar como condición-límite y no de la enfermedad como cuadro nosológico, de la medicina en cuanto componente del existir humano y no de la medicina como práctica profesional. Además, no hay enseñanza posible sobre cómo proceder ética ni deontológicamente porque el autor — no el narrador - aborda conflictos humanos insolubles o que son intratables por el saber teórico; solo la función narrativa los puede abrir y aclarar de manera apropiada o, con expresión de Ricoeur, por la razón narrativa y no la razón teórica(24).

\section{Trasfondo personal}

Aunque no se trata de profundizar ni en Thomas Mann ni en su biografía, de todos modos resulta conveniente recordar que su novela se gestó a raíz de la estadía de seis meses de su esposa Kathia en el Waldsanatorium de Davos-Dorf por una afección tuberculosa. Entre el 15 de mayo y junio de 1912 el escritor la visitó por tres semanas y, aunque a él también se le prescribió una cura formal por una inflamación pulmonar, a diferencia de Hans Castorp no aceptó y retornó a su hogar en Alemania. Diariamente intercambiaron impresiones marido y mujer sobre el Dr. Friedrich Jessen y su miríada de huéspedes de todas las nacionalidades y condiciones espirituales, tal como lo hicieron Hans y su primo Joachim Ziemßen a su llegada. Las innumerables cartas que se escribieron a continuación, aunque perdidas definitivamente, le permitieron obtener una visión, de primera fuente y desde el interior, de la vida en un Sanatorium destinado a una burguesía acomodada.

En el verano de 1913 comenzó su escritura, muy poco tiempo después de terminar su extraordinario cuento largo de muerte, belleza, arte y descomposición "La muerte en Venecia” (25). De ahí que proyectara "la contrapartida humorística", una nouvelle "mezcla de muerte y diversión", sarcástica y grotesca, un Satyrspiel. "La fascinación por la muerte, el triunfo del embriagador desorden sobre una vida dedicada al orden más excelso, descrito en 'La muerte en Venecia', debía plasmarse en clave humorística", dijo, y agregó "lo que ha aprendido a entender (Hans Castorp) es que toda salud superior tiene que pasar por la profunda experiencia de la enfermedad y la muerte (...). Hacia la vida, le dice en una ocasión Hans Castorp a Madame Chauchat, hacia la vida hay dos caminos: uno es el habitual, directo y formal. El otro es malo, lleva sobre la muerte, y ese es el camino genial. Esa concepción de la enfermedad y la muerte como un paso necesario hacia el saber, la salud y la vida, convierte 'La montaña mágica' en una novela de iniciación...”(26).

Queda claro que toda la trama nace de su imaginación y poder creativo y supera con mucho sus experiencias reales. Acaso debido en parte a aflicciones personales, intereses literarios - como la redacción de "Las memorias del estafador Felix Krull”- y la Gran Guerra, la fue postergando, madurando y con ello cambiando de perspectiva, énfasis y alcances. Lo proyectado fue ampliamente rebasado por el producto final y, aunque no es este el momento de una interpretación de sus motivaciones inconscientes, quizás le sirvió de terapia para curarse espiritualmente de sus ambigüedades, perplejidades y desazones, que fue lo que no pudo conseguir su inolvidable Hans Castorp (27-29).

\section{El pacto de confianza}

La ética médica tiene una orientación tanto práctica como a la investigación, pero la meta exclusiva del Sanatorium Berghof es el cuidado y la curación, aunque proclama con insistencia sustentarse y aplicar la ciencia médica más estricta. Su dimensión ética es práctica, puesto que actúa, modifica e intenta transformar activamente la vida de sus enfermos.

Su base radica en un pacto de cuidados basado en la confianza. Esta confianza no busca promoverse activamente en las primeras entrevistas, sino descansa en el prestigio social de la medicina y del establecimiento; está más allá de toda duda porque su fundamento es cultural e histórico. Ahora bien, hay una disimetría inicial profunda que crea una distancia debido a que es el médico el único que sabe, sabe hacer y prescribe. El paciente in- 
tenta nivelarse relatando sus sufrimientos y apela al médico sin llegar, casi nunca, a demandar o incluso exigir de manera franca su diagnóstico, pronóstico ni su curación; a lo más, él expresa una promesa de seguir y mantener el tratamiento indicado.

A su vez el médico - el consejero aúlico doctor Behrens-, tibia e inconstantemente, procura acercarse e igualar las condiciones entre ambos integrantes de la díada, por medio de compartir ciertos hallazgos médicos y terapéuticos o preocuparse tangencialmente por las penurias individuales. Contrariamente y con absoluta firmeza, se compromete a tratar con todo su arte, asistir sin flaquear y acompañar al paciente durante todo su curso, aun hasta su muerte. Existe pues la promesa del enfermo y el compromiso del médico que culmina en una alianza contra el invasor común que es la enfermedad.

Este pacto es notoriamente frágil y se trastoca con facilidad en desconfianza o sospecha. El paciente exige demasiado, no solo la recuperación sino la mejoría y aun la felicidad, por no hablar de la ilusión de la inmortalidad; además, teme el poder omnipotente del médico, su fuerza moral para convencer persistir en el tratamiento e, incluso, de sus propósitos de lucrar con su persona. Por su parte, el médico recela de la capacidad de autoengaño de los enfermos, de la debilidad espiritual de ellos, de la intrusión de terceros (familiares), otros facultativos no especialistas, medicinas alternativas y de las fuerzas económicas externas interesadas en destruir o poner en riesgo los esfuerzos curativos, porque no hay una relación unidireccional entre médico y administración de salud, el médico es, en suma, solo un empleado.

\section{La prudencia}

El primer nivel —el más importante- del juicio médico es el prudencial. La phrónesis griega, inherente a la medicina, significaba que la dimensión práctica se jugaba en situaciones singulares e irrepetibles, por cuanto el paciente es individual tanto como el médico y, en este sentido, era propia de los atributos de la tékhne, que trata con lo particular, y no era episteme, ciencia que se ocupaba de lo universal. Es esta prudencia o sa- biduría práctica — no teórica - la que sigue estrictamente el actuar médico en Berghof y que se sustenta en atributos intuitivos aplicados por el profesional, y este conocimiento proviene en parte de lo aprendido en sus estudios universitarios, pero mayoritariamente del ejercicio sostenido y reanudado diariamente junto al lecho del paciente. Lo que sucede es que la meta de esta medicina práctica está focalizada en el sufrimiento decididamente somático, aunque lo psíquico también juega un papel pero bastante menor, y toda otra consideración es secundaria o se sustenta en ella.

Ahora bien, que la prudencia guíe el pacto de confianza no significa descansar en una beneficencia de buena voluntad o caridad. Posee reglas producto del mismo ejercicio, practicadas durante ańos, y que son preceptos y no normas, como sucede en el nivel deontológico. Estos preceptos se pueden resumir en el reconocimiento del carácter único e insustituible de cada enfermo y el respeto debido a su persona. Aunque es innegable que el médico considera al paciente dependiente y subordinado en cuanto a su situación de enfermo ( $y$ en ocasiones ramplón en sus atributos personales y morales), también es innegable que reconoce la dignidad que posee siempre y en toda ocasión por estar atacado por un mal, dignidad que es más primordial en las situaciones extremas de empeoramiento y agonía. A esta dignidad se la puede llamar éticamente "estima de sî": el doctor Behrens se la reconoce especial y señaladamente a Hans Castorp, Madame Chauchat, Joachim Ziemßen, Mynheer Peeperkorn, por nombrar los personajes más destacados.

\section{El contrato médico}

Acabamos de ver el nivel prudencial del juicio médico en el Berghof, ahora hay que ascender al nivel deontológico. El pacto de confianza o confianza recíproca y la promesa de mantener ese pacto se elevan de rango desde lo interpersonal al convenio, desde las relaciones interindividuales a las relaciones contractuales. Esto significa que la clínica en "la montaña mágica" no solo se rige por lo particular de cada caso sino también universaliza lo que conocimos más arriba como preceptos. Frente a las virtudes o excelencias de la práctica diaria de la prudencia, que se materializan en los 
preceptos, están los deberes que siguen normas y que se expresan en máximas de acción.

Resulta difícil precisar la norma históricamente establecida del secreto médico, de la prohibición de romperlo o trasgredirlo, porque en el nivel prudencial tampoco se priorizaba con especial énfasis la dimensión de la confidencialidad. Con frecuencia, no solo los pacientes intercambian intimidades sobre sus padecimientos y pronósticos sino el equipo médico del doctor Behrens y su asistente Krokovski se expresa con bastante indiscreción en sus conversaciones. Lo mismo vale para la máxima de la verdad compartida entre enfermo y doctor. Nunca el paciente está seguro de que se le informe de manera auténtica y veraz sobre su condición y el médico no se siente obligado a hacerlo de rutina o en todo su alcance o gravedad. No hay por tanto una vinculación íntima entre ambas normas, secreto profesional y deber a la verdad, porque las dos máximas de acción rigen de manera tácita, sin mayor cuidado y rigor por los integrantes del contrato. ¿Posibilidad de informarse, sugerir o rechazar terapias alternativas? El doctor Krokovski no solo da conferencias sobre "disección psíquica" (Seelenzergliederung), sino trata a alguno de sus oyentes por este medio, especie de psicoanálisis silvestre que no es considerado una terapia auténtica, sino un coadyuvante experimental sin mayores pretensiones y, por tanto, como no forma parte del tratamiento propiamente tal, es tolerado por todos sin mayores preguntas. Otro asunto es el neumotórax practicado por medio de una inyección de nitrógeno como medida desesperada de ayuda, que es aplicado en ausencia de una explicación detallada ni tras haber discutido la técnica de manera proporcional a su potencial peligro; sin embargo, nadie cuestiona su utilidad ni tampoco la honestidad del médico al proponerlo; incluso se llega a hacer bromas del procedimiento al denominar "sociedad de los medio pulmones" (Verein Halbe Lunge) a aquellos enfermos que lo portan y exhiben dramáticamente en los pasillos del sanatorio.

¿Qué pasa con la máxima que rige para arbitrar y superar los conflictos? No existe, porque se tiende a ignorarlos, minimizarlos o simplemente soslayarlos. La partida de Joachim Ziemßen de Berghof se produce porque este se enfrenta con determinación al doctor Behrens y le comunica su de- cisión que ya había sido planteada repetidamente con anterioridad, aunque de manera tímida. Behrens acepta e insiste, tras preguntarle si lo hace “A su riesgo y peligro?", en que "efectivamente es un asunto de usted y no mío. Se marcha bajo su propia responsabilidad. Cada uno con lo suyo. Usted viaja sin garantía, yo no respondo de nada (...) Es muy posible que le convenga y que se las arregle usted bien”. Esto es, no hay una norma informalmente establecida que obliga a tratarse aunque no se quiera - no hay un furor sanandi oculto-, pero queda claro que tampoco existen procedimientos explícitos, formales o informales, para dirimir las discrepancias, aprietos y dificultades.

Con esto queda en evidencia que hay una diferencia entre deber de cuidado, que el médico suscribe más allá de toda circunstancia, y deber de curación o resultados, un ardor por alcanzar la salud a toda costa por parte del paciente y, con ello, una amenaza latente sobre el facultativo cuando no la consigue; este deber de curación no solo no es forzoso sino ni siquiera se lo alude al comenzar la cura en el sanatorio.

¿Hay un precepto que fuerce a tomar en cuenta la salud pública? No se puede responder porque se trata de una clínica privada, pero queda la sospecha que no se la considera, ya que el doctor Behrens no sopesa la posibilidad de que Joachim se convierta en potencial peligro para la comunidad al momento de su alta disciplinaria. Además, el asunto de los costes es mencionado, pero como complicación que incumbe exclusivamente a los interesados y no a la sociedad; la sofisticación de los tratamientos y su carga monetaria queda circunscrita al individuo, como se ejemplifica en Lodovico Settembrini, quien se ve forzado a dejar el Berghof por serle imposible seguir sufragándolo.

\section{La toma de decisiones}

En su "pequeña ética”, Ricoeur habló que la ética consiste en un deseo de vivir bien, con y para los otros, en instituciones justas(30). Como la ética médica se inscribe en esta ética general del vivir bien y vivir juntos, lo que la especifica y le da su sello único es que su motivación es el sufrimiento, el sufrimiento a partir de la enfermedad que es 
propia de la condición humana y que en ocasiones la ataca. En el nivel prudencial, el deseo de vivir bien es el deseo de salud; en el nivel deontológico del con y para los otros, es el contrato de cuidado fundado en la confianza e intimidad técnica, y en el nivel de las instituciones, la profesión médica. Lo dicho hasta aquí se cumple en cada uno de los niveles, lo que traduce la eticidad inherente a la medicina practicada en el Berghof.

¿Qué sucede en la toma de decisiones? La situación original es la incertidumbre que es esencial al enfermar, incertidumbre tanto del médico como del enfermo. El paciente maneja su incerteza entregando su confianza casi total en el médico bajo la promesa de ser fiel a las indicaciones, aunque siempre amenazado por los peligros de la mentira piadosa, del engaño de aminorarse la gravedad de su condición, de que su propio bien no coincide con lo que el facultativo entiende por bien -Ziemßen viró de la entrega esperanzada a la infelicidad insoportable, porque el doctor Behrens no estuvo de acuerdo con su concepción de vida buena que lo impulsó a abandonar el recinto; lo contrario sucedió a Castorp, de modo que lo condujo a permanecer siete años.

La incertidumbre exige la elevación al plano de la toma de decisiones que, como hemos visto, atañe poco al paciente, salvo en mantener su promesa de continuar con rigor y fidelidad el tratamiento prescrito. No existe intercambio de argumentos ni contra argumentos, ni resolución de diferencias, ocasionalmente quejas aisladas sobre tópicos particulares (como fecha de alta). El facultativo lleva a cabo todo el proceso en su intimidad, procede del plano general al plano específico, de la regla general del saber científico y el saber-hacer profesional a la decisión tomada en situación única, esto es, a escoger finalmente basándose en sus propios preceptos que aplica diariamente producto de su experiencia clínica. Antes que una argumentación lógica, inductiva, se trata de interpretaciones creativas, originales y únicas. $\mathrm{La}$ culminación de esta reflexión es la prescripción del médico, lo que le faculta para pasar al otro nivel, el nivel de aplicación, que, más aún que el anterior, incumbe solo al médico.

Por decirlo así, el acto médico tiene una finalidad corta muy clara, resolver un sufrimiento, pero una finalidad a largo plazo más difusa o menos posible de alcanzar en la realidad, la restitución a la vida civil en condiciones de llevar una existencia buena, útil, independiente, capaz. Lo que resulta evidente es que nunca se define a la medicina, al menos explícitamente, como una empresa de cuidados de las enfermedades, en tanto atañen a los vínculos que tienen sus miembros con la sociedad como conjunto; de hecho, se sabe casi nada del destino ulterior de los pacientes después de abandonar el recinto; las excepciones la constituyen los casos que pretenden regresar por recaídas o agravamientos finales, quienes proceden a ponerse en contacto directo con su médico por medio de misivas.

\section{Niveles biológico, social y existencial}

La vida humana no tiene solo un sentido biológico, sino igualmente social y existencial(31-33). De los dos primeros se ocupa la ética médica, en cambio el tercero va surgiendo a medida que los pacientes van viviendo "las aventuras de la carne y el espíritu" dentro del sanatorio, en intercambio íntimo con los otros enfermos y sus mentores, mucho más que con los doctores y el ambiente protegido de las enfermeras y personal de salud.

La enfermedad biológicamente considerada tiene un sentido éticamente negativo, es un déficit, carencia, insuficiencia, irregularidad, desviación, que obliga al individuo a desplegarse en un medio reducido cualitativamente diferente al anterior. El valor vital se encuentra menoscabado porque se evalúa entre el sujeto y su capacidad para resolver sus tareas y exigencias biológicas. Es el médico el que ayuda a enfrentar esta capacidad limitada para operar con las amenazas, peligros y disfunciones: es el poder del doctor asistiendo a la impotencia orgánica del enfermo. De ahí la presunción que en ocasiones exhibe el doctor Behrens por este sentimiento de poder del hombre sano y que administra conocimientos frente al paciente que es impotente o está incapacitado, el valor engañoso del que se siente físicamente garantizado frente al valor de inseguridad personal que experimenta el devastado por el mal. Se contraponen la insolencia del sano al avergonzado, despreciado y desairado del enfermo. 
La enfermedad como una anormalidad biológica de ejercicio se distingue de una anormalidad social de uso, la norma interior del ser vivo frente a la norma exterior de lo social, las causas de los procesos orgánicos del sentido de los motivos interpersonales. En otros términos, el vivir en un medio reducido conduce y culmina en una incapacidad o merma para cumplir con los criterios usuales de vivir juntos con otros. Con ello hace su aparición la enfermedad como estigma social y la medicina responde con la exclusión(34). Pero en el Berghof la exclusión adquiere una connotación especial y distintiva: la reclusión. El sanatorio esconde, emboza y oculta a sus discapacitados e introduce una suerte de vidrio opaco ante la amenaza que ellos representan en cuanto recuerdan la fragilidad, la precariedad y la mortalidad. Al estructurarse como una institución médica total, según la expresión de Goffman, éticamente da origen a una mortificación del yo (degradación, humillación, profanación, mutilación), acudiendo a una serie de procedimientos: despersonalización, echando mano a nombrarlos según el grado de su compromiso pulmonar; desidentificación, por medio de actividades aparentemente culturales o lúdicas pero sin ninguna trascendencia para su futuro en la vida exterior; desautonomización, a través de la vigilancia constante aunque disimulada de los actos; destemporalización, mediante una rutina diaria artificial invariable; desexualización, al recurrir a la inhibición de cualquiera muestra de expresión amorosa(35).

Pero la enfermedad tuberculosa no es solo una desestructuración del organismo que ha perdido sus leyes de funcionamiento fisiológico, ni una anormalidad de uso de las normas sociales que rigen el vivir en compañía de los otros, sino una forma diferente de estructuración, una nueva y especial manera de ser-en-el-mundo con sus valores distintivos y propios. Frente al valor vital del organismo, en oposición a las virtudes de la solicitud y procurar por el otro, está la excelencia de la autorrealización personal(36).

Los planos éticos involucrados en el sanatorio Berghof son definidos, aunque en algunos respectos de modo poco preciso. Médicamente está el déficit de la estima de sí en el nivel biológico, el déficit del respeto de sí en el nivel social. Pero los facultativos no consideran el nivel existencial donde aquí el déficit se llama "déficit del coraje de ser". La tuberculosis se expresa en una modificación del Selbstgefühl, sentimiento de identidad de sí-mismo o personal, que se lleva a cabo en un proyecto existencial. Es este Selbstgefühl el que se derrumba en la enfermedad, pero este proyecto no se estanca o detiene, se lanza hacia delante aunque de otra forma, porque la enfermedad tiene un valor positivo y no solo negativo, es posibilidad de realización por sobre posibilidad de desestructuración, es un ideal de perfección junto a un estrechamiento de posibilidades. Las enseñanzas de Settembrini, Naphta y Peeperkorn van señalando y entregando lo que los médicos no saben o desconocen, una estima que es doble: una estima de sustitución y una estima de suplemento, que permiten nuevas y diferentes maneras de estar, abrir y esclarecer el mundo(37-39). Gracias a ello, la vida de Hans Castorp se eleva de "un hijo mimado por la vida", de un "joli bourgeois à la petite tache humide", en un sujeto en que el espíritu vence y sobrevive a la carne - aunque al final, cuando estalle la Gran Guerra y su "fiesta de la muerte", contrariamente y de manera ominosa, "lo que te ha permitido vencer con el espíritu no podrás sobrevivir con la carne”(20).

\section{Fragilidad de la ética médica}

1) La ética médica ejercida en "La montaña mágica" muestra los conflictos, incertidumbres y paradojas que la acosan en la práctica clínica e impiden dar normas estandarizadas, prescripciones unívocas y principios universales de comportamiento, y así la hace particularmente frágil: a) el enfermo no es una cosa y, sin embargo, su cuerpo es parte de la naturaleza física; b) el paciente no es una mercancía ni la medicina un comercio, pero la medicina tiene un precio y es costosa; c) el sufrimiento es privado, pero la salud es pública; d) la enfermedad es una desestructuración, pero el enfermo es un proyecto de vida de autorrealización(31).

2) La moral médica es supuesta, admitida y acatada por todos los participantes del acto terapéutico: enfermo, médico, familia, sociedad en su conjunto. Antes que cuestionarla o polemizar sobre ella, se la practica de forma silenciosa. Parafraseando lo que Aristóteles dijo de la justicia: no 
importa tanto saber lo que es la ética médica sino actuar éticamente. La tradición médica occidental y el prestigio cultural de la profesión son determinantes para esta postura. Que en ocasiones se la ironice, descalifique o desacredite de manera pasajera o ácida, y respecto de puntos particulares, significa que posee fuerza, presencia y vigencia.

3) La ética de la virtud y de la virtuosidad unida al juicio prudente predominan sobre las normas y máximas de acción, sean el secreto médico, la verdad compartida entre médico y paciente, y el asentimiento a los procedimientos terapéuticos. Por así decirlo, el "médico perfecto" es más valorado que el acatamiento por parte del equipo médico a las reglas establecidas de manera obligatoria, aunque el téleios iatrós no constituye una ideología que se proclama apasionadamente, sino solo un ideal al que se aspira juiciosamente.

4) La ética médica se ocupa esencialmente de los planos biológico y social, y, por ello, le importa la estima de sí y el respeto de sí del paciente, aunque con matices. Porque finalmente es el organismo la meta de su accionar, el sufrimiento físico antes que el sufrimiento espiritual, la desorganización somática antes que el desequilibrio emocional. Quizás ese sea el motivo por el que se valore más a la ética del no abandono que a la ética del acompańamiento o cuidado, porque le importe especialmente que el paciente sienta que siempre y en toda ocasión se estará con él antes que detenerse a consolarlo en los instantes de desamparo psicológico, esto es, la confianza antes que la solicitud, procura o cuidado-del-otro (variedad específica de Fürsorge, en terminología de Heidegger) (40).
5) La relación terapéutica es determinante, pero en un sentido técnico antes que personal, es una camaradería itinerante (Weggenossenschaft de von Weizsäcker)(41) que tiene una finalidad bien precisa: aunarse en derrotar al enemigo común que es la enfermedad y no en entablar una relación íntima, porque a esta no se la concibe como causante de su génesis, presentación, curso ni curación. Siguiendo a Aristóteles, la relación médica es una versión de la amistad, pero no amistad por utilidad, ni amistad por placer, sino amistad por reciprocidad, por ser quien se es, como individuo único, aunque sin ponerse como meta la intimidad ni menos la relación amorosa, al ser los participantes de sexo opuesto $(5,8,42-44)$.

6) Las críticas a esta ética médica vienen del narrador y no de los participantes del encuentro terapéutico, ni menos de los representantes de las leyes o de la sociedad. La preferencia por una ética de la vida buena por sobre la de los deberes, por el bien por encima de lo obligatorio, por la estima de sí antes que por el respeto de sí, por los máximos morales a que tiene que aspirar el sujeto como persona con preponderancia a los mínimos morales que necesita alcanzar cualquier individuo al interior de la sociedad, trae problemas y graves. Estos dilemas necesitarán ser enfrentados por otro tipo de ética en otro momento histórico. Llevada a un plano social, es lo que advierte y pronostica este narrador al finalizar su obra, aunque se puede inferir que la ética médica, al igual que la sociedad entera, también puede deslizarse a una lucha de muerte y exterminio entre principios opuestos: "de esta fiesta de la muerte, de esta mala fiebre que incendia en torno tuyo (Hans Castorp) el cielo de esta noche lluviosa, ¿se elevará el amor algún día?". 


\section{Referencias}

1. Pellegrino ED, Thomasma DC. For the patient's good: The restoration of beneficence in health care. New York: Oxford University Press; 1988.

2. Pellegrino ED. The metamorphosis of medical ethics. A 30-year retrospective. JAMA 1993; 269: 1158-1162.

3. Toulmin S. How medicine saved the life of ethics. Perspect Biolog Med (Chicago)1982; 25: 736-750.

4. Rothman DJ. Strangers at the bedside: A history of how law and bioethics transformed medical decision making. New York: Basic Books; 1991.

5. Aristóteles. Ética a Nicómaco. Madrid: Centro de Estudios Constitucionales; 1985.

6. Ricoeur P. Les trois niveaux du jugement médical. Esprit 1996; 12: 21-33.

7. Laín Entralgo P. La curación por la palabra en la antigüedad clásica. Madrid: Revista de Occidente; 1958.

8. Laín Entralgo P. La relación médico-enfermo. Historia y teoría. 2a. Edición. Madrid: Alianza; 1983.

9. Cassell EJ, Siegler M, (editors). Changing values in medicine. New York: University Publications of America; 1979 .

10. Drane JF. Becoming a good doctor: the place of virtue and character in medical ethics. Kansas: Sheed and Ward; 1988.

11. Fraisse J-C. Philia. La notion d'amitié dans la philosophie antique. Paris: Vrin; 1984.

12. Heidegger M. Der Ursprung des Kunstwerkes. En: Heidegger M. Gesamtausgabe 5. Frankfurt: Klostermann; 1984: 7-68.

13. Figueroa G. Lo ominoso revisitado. Freud y "La vuelta de tuerca" de Henry James. Rev Chil Neuro-Psiquiat 2000; 38: 237-254.

14. Figueroa G. El trastorno mental de Hamlet: Un diálogo con H Tellenbach. Rev Chil Neuro-Psiquiat 2000; 38: $72-83$.

15. Tellenbach H. Schwermut, Wahn, und Fallsucht in der abendländischen Dichtung. Hürtgenwald: Guido Pressler; 1983.

16. Figueroa G. Triunfo, culpa y muerte reconsiderados: la interpretación de un sueño en "Fresas salvajes" de Ingmar Bergman. Rev Chil Neuro-Psiquiat 2002; 40: 210-237.

17. Figueroa G. Virginia Woolf: enfermedad mental y creatividad artística. Rev Méd Chile 2005; 133: 13811388 .

18. Heidegger M. Brief über den "Humanismus". Gesamtausgabe 9. Frankfurt: Klostermann; 1976: 313-364.

19. Heidegger M. Zollikoner Seminare. Protokolle-Zwiegespräche-Briefe. 2. Auflage Frankfurt: Klostermann; 1994.

20. Mann T. Der Zauberberg. Frankfurt: Fischer; 1945.

21. Goethe JWv. Wilhelm Meisters Lehrjahre. Sämmtliche Werke IV. Stuttgart: Cota; 1940.

22. Ricoeur P. Temps et récit II. La configuration dans le récit de fiction. Paris: Seuil; 1984.

23. Thieberger R. Der Begriff der Zeit bei Thomas Mann, von Zauberberg zum Joseph. Baden-Baden: Verlag für Kunst und Wissenschaft; 1962.

24. Ricoeur P. Temps et récit I. L 'histoire et de récit. Paris: Seuil; 1984.

25. Mann T. Der Tod in Venedig. 22. Aufl. Frankfurt: Fischer; 1998.

26. Mann T. Einführung in den Zauberberg. Für Studenten der Universität Princeton. Als Vorwort. En: Mann T. Der Zauberberg. Frankfurt: Fischer; 1945: 7-20.

27. Mann T. Bekenntnisse des Hochstaplers Felix Krull. Frankfurt: Fischer; 1954.

28. Figueroa G. Enfermedad creativa. Anuario Escuela de Medicina de la Universidad de Valparaíso 1993; 2: 135144.

29. Anzieu D. Les cinq phases du travail créateur. En: Anzieu D. Le corps de l'oeuvre. Essais psychanalytiques sur le travail créateur. Paris: Gallimard; 1981: 91-211.

30. Ricoeuer P. Soi-même comme un autre. Paris: du Seuil; 1990.

31. Ricoeur P. Le juste 2. Études, lectures et exercices de étique apliqué. Paris: Esprit; 2001.

32. Sartre J-P. L'être et le néant. Essai d'ontologie phénomenologique. Paris: Gallimard; 1943.

33. Zubiri X. Tres dimensiones del ser humano: individual, social, histórica. Madrid: Alianza; 2006

34. Foucault M. Le pouvoir psychiatrique. Cours au Collège de France 1973-1974. Paris: Seuil/Gallimard; 2003.

35. Goffman E. Asylums. Essays on the social situation of mental patients and other inmates. New York: Doubleday \& Company; 1961.

36. Figueroa G. Responsabilidad profesional: máximos, mínimos, excelencia y veracidad. Rev Méd Chile 2006; 134: 233-239. 
37. Ricoeur P. Parcours de la reconnaissance. Trois études. Paris: Éditions Tock; 2004.

38. Figueroa G. Los fundamentos del análisis existencial. Rev Chil Neuro-Psiquiat 1995; 33: 21-29.

39. Figueroa G. Problemas de la psicoterapia existencial. Rev Psiquiatría Clínica 1991; 28: 45-59.

40. Heidegger M. Sein und Zeit. 10. Aufl. Tübingen: Niemeyer; 1963.

41. Weizsäcker WV. Der Arzt und der Kranke. Stücke einer medizinischen Anthropologie. Gesammelte Schriften. Band 5. Frankfurt: Suhrkamp; 1987.

42. Laín Entralgo P. Sobre la amistad. Madrid: Espasa-Calpe; 1985.

43. Laín Entralgo P. Amor al hombre y amor al arte en la medicina hipocrática. En: Laín Entralgo P. Ciencia, técnica y medicina. Madrid: Alianza; 1986: 218-227.

44. Binswanger L. Grundformen und Erkenntnis menschlichen Daseins. 5. Auflage. München: Ernst Reinhardt; 1962.

Recibido: 30 de julio de 2011

Aceptado: 12 de agosto de 2011 